\title{
KAJIAN MODEL INOVASI AGRIBISNIS KOMODITAS KOPI (STUDI KASUS DI 'KOPI SEBAGAI')
}

\author{
STUDY OF AGRIBUSINESS INNOVATION MODELS \\ OF COFFEE COMMODITIES \\ (CASE STUDY IN 'KOPI SEBAGAI')
}

\author{
Nabilla Nur'Azizah Manika Putri*1, Gema Wibawa Mukti² \\ ${ }^{1}$ Program Studi Agribisnis, Fakultas Pertanian, Universitas Padjadjaran, Jl. Raya Bandung- \\ Sumedang Km. 21 Jatinangor, Kab. Sumedang 45363 Jawa Barat \\ *E-mail: nabilla16005@mail.unpad.ac.id \\ (Diterima 09-01-2020: Disetujui 16-01-2020)
}

\begin{abstract}
ABSTRAK
Tingkat konsumsi kopi di Indonesia mencapai 4,6 juta kemasan dan Indonesa berada di urutan ke-6 negara dengan konsumsi kopi terbesar di dunia. Varian kopi yang sudah terkenal sampai tahun 2019 sangat beragam, berasal dari berbagai macam daerah seperti Jawa Kopi, Kopi Gayo, dan lain - lain. Peningkatan konsumsi kopi di Indonesia juga didukung dengan globalisasi yang menimbulkan banyak Kedai Kopi berdiri di Indonesia khususnya Kota Bandung. Kedai Kopi di Kota Bandung yang beragam menyebabkan persaingan antar kedai kopi, hal ini menuntut setiap pengusaha Kedai Kopi untuk melakukan inovasi pada bisnisnya. Penelitian ini bertujuan untuk mengkaji bagaimana inovasi bisnis yang digunakan salah satu Kedai Kopi di Kota Bandung yaitu 'Kopi Sebagai' menggunakan Bisnis Model Kanvas dalam mengembangkan bisnisnya. Penelitian dilakukan menggunakan metode kualitatif, teknik wawancara mendalam, dan dokumentasi. Analisis Lingkungan Model Bisnis dilakukan untuk melihat keadaan lingkungan bisnis untuk melihat keadaan pasar, industri, tren kunci, dan ekonomi makro. Hasil penelitian menunjukkan 'Kopi Sebagai' menerapkan Bisnis Model Kanvas berdasarkan Proporsi Nilai dengan tujuan menyampaikan nilai 'sempurna' dan fokus utama target konsumen adalah orang dewasa, dengan memberikan fasilitas, pelayanan, dan kualitas kopi terbaik hasil panen kebun Pangalengan.
\end{abstract}

Kata kunci: Bisnis Model Kanvas, Inovasi Agribisnis, Lingkungan Model Bisnis

\section{ABSTRACT}

The level of coffee consumption in Indonesia reaches 4.6 million packages and Indonesia ranks 6th in the world with the largest coffee consumption in the world. Variants of coffee that have been famous until 2019 are very diverse, originating from various regions such as Java Coffee, Gayo Coffee, and others. The increase in coffee consumption in Indonesia is also supported by globalization which has caused many Coffee Shops to be established in Indonesia, especially in the city of Bandung. Coffee shops in the diverse city of Bandung cause competition among coffee shops, this requires every Coffee Shop entrepreneur to innovate in his business. This study aims to examine how the business innovation used by one of the Coffee Shops in Bandung, namely 'Coffee As' uses the Business Model Canvas in developing its business. The study was conducted using qualitative methods, in-depth interview techniques, and documentation. Business Model Environmental Analysis is carried out to see the state of the business environment to see the state of the market, industry, key trends, and macroeconomics. The results show that 'Coffee As' applies the Business Model Canvas based on Value Proportion with the aim of conveying the value of 'perfect' and the main focus of the target consumer is adults, by providing facilities, services, and the best quality coffee yields from the Pangalengan plantation.

Keywords: Agribusiness Innovation, Business Model Canvas, Business Environment Model 


\section{PENDAHULUAN}

Perkembangan industri salah satunya didukung oleh Globalisasi, dan Indonesia menjadi salah satu pendukung berkembangnya industri Kedai Kopi dan Ekspor Kopi. Tingkat konsumsi kopi di Indonesia pada tahun 2016/2017 mencapai 4,6 juta kemasan dengan berat $60 \mathrm{Kg}$ yang menyebabkan Indonesia berada di posisis ke-6 dalam daftar negara konsumsi kopi terbesar di dunia (Internasional Coffee Organization, 2018). Perkembangan tersebut menimbulkan persaingan ketat bagi pelaku usaha pada bisnis produk minuman olahan kopi, persaingan tersebut yang memicu setiap negara utnuk memperkuat sumberdayanya agar dapat tetap bertahan dalam persaingan, Indonesia masuk kedalam persaingan tersebut sehingga Indonesia dituntut untuk dapat menyediakan segala kebutuhan konsumen dengan baik.

Menurut Osterwalder dan Pigneur (2012), pemahaman mengenai lingkungan model bisnis berpengaruuh terhadap model bisnis yang didesain dan dijalankan agar mendapatkan hasil yang kuat dan kometitif. Bentuk keuntungan yang kompetitif dalam persaingan berhubungan dengan sumber daya manusia, kreativitas, dan pemikiran yang kreatif (Petersen,
2013). Cara pemikiran kreatif akan menimbulkan ide-ide inovasi yang dapat mengembangan sebuah usaha, karena persiangan tidak hanya terjadi karena hal kuantitas namun juga kualitas, keterampilan pemasaran, status, potensi kelembagaan pendukung produksi, dan politik perdagangan (Suradisastra, dkk, 2014). Hal-hal tersebut perlu dipenuhi dan diperhatikan oleh pelaku usaha khususnya usaha Kedai Kopi di Kota Bandung. Fokus utama inovasi adalah terciptanya sebuah ide atau gagasan baru yang dapat diimplementasikan sebagai atau kedalam proses yang baru dan memiliki tujuan untuk memberikan juga menyalurkan nilai pelanggan yang lebih baik (Hartini, 2012).

Hasil Klasifikasi Baku Lapangan Usaha Indonesia (KBLI) dan BPS dalam Statistik Industri Besar dan Sedang Jawa Barat tahun 2015 bahwa jumlah unit industri besar sedang pada industri minuman dan makanan dari tahun 20102015 mengalami peningkatan jumlah unit sebagaimana terlihat pada Tabel 1.

Kedai Kopi yang berada di Kota Bandung berjumlah 366 pada tahun 2015 (Prillyana, 2017), konsep yang digunakan untuk Kedai Kopi juga bermacam-macam, dengan begitu model inovasi sangat berpengaruh terhadap pencapaian usaha, menciptalan pasar baru bahkan 
menghasilkan kualitas produk baru yang baik. 'Kopi Sebagai' adalah salah satu Kedai Kopi yang berada di Kota Bandung, minuman olahan kopi yang dijual berasal dari hasil panen kebun milik perusahaan sendiri di Pangalengan. 'Kopi Sebagai' berdiri sejak April 2019 dan masih dalam tahap perkembangan yang baru akan di resmikan pada akhir tahun 2019. Dalam hal ini, tujuan penelitian ini untuk mengetahui bagaimana inovasi bisnis yang digunakan 'Kopi Sebagai' dalam mempertahankan usahanya di tengah persaingan Kedai Kopi di Kota Bandung.

Tabel 1. Jumlah Industri Makanan Minuman Besar Sedang di Jawa Barat tahun 2010 - 2015

\begin{tabular}{|c|c|c|c|c|c|c|}
\hline \multirow{3}{*}{$\underset{\text { ri }}{\text { Indust }}$} & \multicolumn{6}{|c|}{ Tahun } \\
\hline & 201 & 201 & 201 & 201 & 201 & 201 \\
\hline & 0 & 1 & 2 & 3 & 4 & 5 \\
\hline \multirow{4}{*}{$\begin{array}{c}\text { Maka } \\
\text { nan }\end{array}$} & 1.0 & 1.0 & 1.0 & 1.0 & 1.0 & 1.0 \\
\hline & 35 & 06 & 79 & 11 & 11 & 55 \\
\hline & Uni & Uni & Uni & Uni & Uni & Uni \\
\hline & $\mathrm{t}$ & $\mathrm{t}$ & $\mathrm{t}$ & $\mathrm{t}$ & $\mathrm{t}$ & $\mathrm{t}$ \\
\hline \multirow{3}{*}{$\begin{array}{l}\text { Minu } \\
\text { man }\end{array}$} & 73 & 74 & 79 & 95 & 93 & 96 \\
\hline & Uni & Uni & Uni & Uni & Uni & Uni \\
\hline & $\mathrm{t}$ & $\mathrm{t}$ & $\mathrm{t}$ & $\mathrm{t}$ & $\mathrm{t}$ & $\mathrm{t}$ \\
\hline
\end{tabular}

Sumber: Statistik Industri Besar dan Sedang Jawa Barat 2015 (Buku 1)

\section{METODE PENELITIAN}

Penelitian dilaksanakan selama bulan Agustus-September tahun 2019 di 'Kopi Sebagai" yang berlokasi di Jalan Ciliwung No. 9 Kota Bandung. objek dalam penelitian adalah Model Inovasi Agribisnis Komoditas Kopi dengan Subjek adalah pelaku yang berhubungan dengan 'Kopi Sebagai'. Penelitian dilakukan dengan desain kualitatf, tujuannya untuk menghasilkan uraian secara mendalam mengenai tulisan, ucapan, dan perilaku yang diamati dari individu atau kelompok secara utuh, komprehensif, dan holistik. Metode yang dilakukan dalam penelitian untuk mendapatkan informasi dengan wawancara mendalam atau in-depth interview.

Data primer yang dilakukan dalam penelitian adalah hasil dari wawancara mendalam bersama dengan pemilik perusahaan, manajer perusahaan, kepala perkebunan perusahaan, dan pelanggan 'Kopi Sebagai'. Data Sekunder yang digunakan didapat melalui hasil literatur berupa buku, jurnal, penelitiam terdahulu, dan internet yang informasinya valid. Analisis Data dilakukan melalui Reduksi Data, Penyajian data, hingga Penarikan Kesimpulan. Alat analisi data menggunakan Bisnis Model Kanvas (Business Model Canvas), dilakukan untuk menjelaskan model inovasi bisnis yang digunakan 'Kopi Sebagai’ kemudian menggambarkannya dalam 9 elemen BMC.

Inovasi diterapkan dalam model bisnis dapat membantu perusahaan untuk melakukan perkembangan karena, (1) Inovasi merupakan sumber yang jarang 
digunakan untuk masa depan, sehinggan ketika digunakan akan memiliki dampak yang cukup besar, (2) Pihak pesaing akan lebih sulit meniru aktivitas dan juga produk yang dilakukan karena menggunakan sistem yang baru, (3) Inovasi model bisns sebagai alat yang kompetitif dan kuat didalam sebuah persaingan danseringkali ancaman kompetitif berasal dari bataan tradisional industri (Amitt dan Zott, 2010). Selain itu juga dilakukan analisis eksternal dengan melihat kondisi bisnis di lingkungan 'Kopi Sebagai' menggunakan Analisis Lingkungan Model Bisnis.

\section{HASIL DAN PEMBAHASAN}

\section{Profil 'Kopi Sebagai'}

'Kopi Sebagai' adalah Kedai Kopi yang dibangun oleh PT. Agro Investama untuk memasarkan hasil produk minuman olahan kopi dari kebun Pangalengan milik perusahaan. 'Kopi Sebagai' didirikan pada bulan April tahun 2019 yang berlokasi di Jalan. Ciliwung No.9 Riau, Kota Bandung. Bangunan 'Kopi Sebagai tergabung dengan sebuah restoran miliki PT. Agro Investama yaitu Nice Meat yang memasarkan hasil produk olahan daging dari peternakan di Malangbong. Garut milik perusahaan.

\section{Analisis Lingkungan Model Bisnis}

Analisis Lingkungan Model Bisnis dilakukan untuk melihat bagaimana keadaan di sekitar bisnis yang berpengaruh dalam membangun model bisnis dengan memperhatiakn Kekuatan Pasar, Kekuatan Industri, Tren Kunci, dan Kekuatan Ekonomi Makro (Osterwalder dan Pigneur, 2012).

1) Kekuatan Pasar

Perusahaan menyadari mengenai isu pasar yang sedang berkembang mengenai masuknya budaya barat karena adanya globalisasi yang menyebabkan adanya perubahan sikap, perilaku, komunikasi, industrialiasi, urbanisasi, dan teknologi di Indonesia. Perubahan perilaku yang terjadi di Indonesia salah satunya adalah peningkatan minat belanja menjadi lebih konsumtif, hal ini karena masyarakat yang biasanya membeli sesuatu sekedar memenuhi kebutuhan sekunder namun saat ini menjadikannya sebagai kebutuhan primer, selain itu juga dikarenakan untuk memperhitungkan prestise atau gengsi. Perilaku tersebut juga berlaku terhadap kegiatan mengkonsumsi minuman olahan kopi yang mulai menjadi sebuah life style di kalangan masyarakat. Selain itu, perilaku masyarakat menjadi konsumtif ditandai dengan adanya pemanfaatan waktu senggang, di mana hal tersebut 
menjadi kebutuhan tersendiri bagi beberapa orang untuk beristirahat sejenak dari rutinitas kerja ataupun untuk mengekspresikan simbol ataupun gaya hidupnya (Solikatun, dkk, 2015)

'Kopi Sebagai' memiliki target pasar yang spesifik yaitu orang dewasa dengan rentan umur 18 - 45 tahun, dengan status ekonomi A - A+. Strategi mempertahankan konsumen yang dilakukan dengan melakukan kerjasama dengan Urbncase yang menjual perlengkapan bersepeda, karena target utama konsumen 'Kopi Sebagai' adalah anggota komunitas sepeda Brompton. Kebutuhan dan Permintaan di lingkungan 'Kopi Sebagai' adalah kenyamaman, baik dalam pelayanan, fasilitas, lokasi ataupun cita rasa yang dijual. Upaya menarik dan mempertahankan konsumen, 'Kopi Sebagai' melakukan Biaya Berpindah secara fokus kepada komunitas sepeda yaitu Komunitas Sepeda Brompton dengan mengadakan event bersepeda bersama dan juga memberikan brunch (breakfast and lunch) kepada anggota komunitas yang mengikuti event.

2) Kekuatan Industri

'Kopi Sebagai' menggunakan konsep yang berhubungan dengan kegiatan sepeda. Di Kota Bandung terdapat beberapa Kedai Kopi yang menggunakan konsep dan kerja sama dengan komunitas sepeda seperti Yumaju, Kamar Tujuh Kopi, dan lain-lain. Namun 'Kopi Sebagai' adalah satu-satunya Kedai Kopi yang memiliki hubungan dengan Komunitas Sepeda Brompton. 'Kopi Sebagai' menjadi salah satu Pemain Baru dalam industri minuman olahan kopi di Kota Bandung, selain itu juga ada Kedai Kopi lain yang menjadi Pemain Baru di lingkungan sekitar 'Kopi Sebagai' yaitu 'Lotu Coffee' namun memeliki target konsumen dan konsep yang berbeda. Perusahaan menyadari akan ada produk ataupun jasa yang akan menggantikan tren minum kopi pada saat ini, yaitu produk produk berupa teh, coklat, dan susu. Hal ini disebabkan karena semakin banyak minuman yang baru muncul dengan bahan-bahan dasar teh, seperti minuman thai tea, ataupun susu seperti brown sugar milk dengan tambahan topping yang beragam.

3) Tren Kunci

Perusahaan memperhatikan tren mengenai masyarakat dan budaya, teknologi, regulasi, dan ekonomi makro untuk meninjau perkembangan bisis kedepannya. Tren masyarakat saat ini mendukung perkembangan Kedai Kopi karena gaya hidup masyarakat yang melakukan manifestasi dengan nongkrong 
di sebuah kafe. Tekonologi yang digunakan untuk membuat minuman olahan kopi saat ini berpengaruh terhadap pertumbuhan Kedai Kopi. 'Kopi Sebagai' menggunakan teknologi pendukung dari mulai kegiatan hulu hingga hilir. Teknologi yang digunakan untuk proses hilir berupa alat pembuat espresso, steam milik untuk pembuatan latte, dan juga sudah menggunakan mesin kasir otomatis dengan iPad.

Peraturan yang dapat memengaruhi perkembangan Kopi yaitu adanya peraturan Nomor 16/M-IND/PER/5/2017 mengenai lembaga penilaian kesesuaian dalam rangka pemberlakuan dan pengawasan SNI Kopi Instan secara wajib, tujuannya untuk mengantisipasi serbuan impor produk kopi yang sudah mulai menguasai pasar domestik (Kementerian Pertanian, 2017). Sedangkan tren sosio - ekonomi saat ini mengenai bisnis yang berbasis lifestyle dan experience. Masyarakat sekarang lebih banyak mengeluarkan pendapatan juga untuk konsumsi terutama remaja dan ibu - ibu, ketika sedang mengalami peningkatan penghasilan akan mengeuarkannya untuk harga makanan yang lebih tinggi dengan kualitas yang lebih baik dibandingkan ketika pendapatan sedang stagnan.
4) Kekuatan Ekonomi Makro

Kondisi pasar secara global diperkirakan oleh Kementerian Perekonomian bahwa peningkatan permintaan kopi menjadi 2 kali lipat pada tahun 2045 (Kementerian Perekonomian, 2018), namun penggunaan lahan kopi diproyeksikan hanya dapat dugunakan setengah lahan pada tahun 2017. Rata-rata produksi kopi Arabika adalah 1,666 USD/Ton dan kopi Robusta 9,37 USD/Ton. Modal yang digunakan perusahaan berasal dari modal pribadi pemilik perusahaan itu sendiri karena masih cukup untuk memenuhi kebutuhan dan pembangunan bisnis. Kopi yang digunakan untuk memproduksi minuman berasal dari perkebunan milik perusahaan di Pangalengan juga memaksimalkan modal yang dikeluarkan oleh perusahaan. Keadaan insfrastruktur di Kota Bandung juga memengaruhi perkembangan Kedai Kopi, 'Kopi Sebagai' berada di pertengahan kota dan akses jalur yang mudah ditemukan oleh konsumen.

\section{Analisis Bisnis Model Kanvas}

Analisis BMC diolah dari hasil wawancara dengan 4 pihak perusahaan yang berhubungan dengan penelitian yaitu pemilik, dua manajer, dan satu kepala lapangan. Selain itu juga data diperoleh 
dari hasil wawancara dengan konsumen 'Kopi Sebagai'.

\section{1) Customer Segments}

Customer Segments menentukan target konsumen untuk 'Kopi Sebagai'. Target konsumen dari 'Kopi Sebagai' adalah orang dewasa yang sudah memiliki penghasilan tetap dengan rata-rata penghasilan Rp6 juta hingga lebih dari Rp8 juta, menyukai olahraga sepeda khususnya sepeda Brompton. 'Kopi Sebagai' juga menentukan target konsumen yang datang ke 'Kopi Sebagai' adalah orang-orang yang memiliki pekerjasaan sehingga waktu untuk menetap tidak terlalu lama dan menyebabkan perputaran uang yang lebih cepat.

\section{2) Value Proposition}

'Kopi Sebagai' adalah Kedai Kopi yang melakukan kerjasama dengan komunitas sepeda Brompton di Kota Bandung. terdapat beberapa Value Proposition yang diberikan kepada konsumen. Pertama, minuman kopi yang dijual berasal dari hasil panen Kebun Pangalengan milik perusahaan sendiri yang meyakinkan konsumen bahwa produk yang dijual sudah terjamin kualitas dan cita rasanya. Kedua, 'Kopi Sebagai' sangat mementingkan kenyamanan konsumen dengan memberikan fasilitas dan pelayanan yang terbaik. Fasilitas yang disediakan mulai dari tempat duduk yang nyaman, internet, mushola, dan toilet, segala fasilitas yang diberikan juga sangat terjaga kebersihannya. Ketiga, akses yang untuk mendapatkan 'Kopi Sebagai' juga mudah ditemukan oleh konsumen. lokasi 'Kopi Sebagai' berada di sebelah jalan besar yang sering dilewati oleh masyrakat. 3) Channels

'Kopi Sebagai' memanfaatkan media sosial sebagai media promosi dan evaluasi. Konsumen dapat mengakses informasi mengenai 'Kopi Sebagai' dari media online Instagram ataupun google, selain itu juga konsumen dapat melakukan interaksi langsung dengan contact person di instagram ataupun nomor yang terterda di gooogle 'Kopi Sebagai'. Kegiatankegiatan bersama dengan anggota komunitas sepeda Brompton juga dilakukan perusahaan untuk memperluas pasar.

\section{4) Customer Relationships}

Hubungan yang dibangun oleh 'Kopi Sebagai' dengan konsumen melalui pelayanan dan fasilitas yang diberikan. Selain konsumen dari anggota komunitas sepeda juga terdapat konsumen lain dari masyarakat luas ataupun pekerja kantoran disekitar lokasi 'Kopi Sebagai'. Fasilitas stop kontak juga disediakan berdekatan 
dengan setiap tempat duduk agar memudahkan konsumen yang membutuhkan. Komunitas sepeda brompton dan pihak perusahaan juga melakukan kegiatan bersepeda bersama yang dilakukan mulai dari 'Kopi Sebagai' hingga kebun Pangalengan dan memberikan brunch (breakfast and lunch) untuk peserta yang mengikuti kegiatan, dan memberikan kesempatan pada peserta untuk melakukan sendiri panen di kebun Pangalengan hingga mengolah minuman kopi secara manual.

\section{5) Revenue Streams}

Keuntungan yang diperoleh oleh 'Kopi Sebagai; berasal dari penjualan minuman kopi, minuman non kopi, dan juga croissant. Pembyaran dapat dilakukan menggunakan uang tunai, debit, atauupun kredit, dalam hal ini 'Kopi Sebagai' tidak memberikan potongan harga, sehigga keuntungan yang diperoleh berasal dari pendapatan dari hasil penjualan dan biaya pelayanan.

\section{6) Key Resources}

Sumber daya yang dimiliki 'Kopi Sebagai' adalah barista dan juga pihak pihak yang berhubungan dengan 'Kopi Sebagai' di PT. Agro Investama yaitu pemilik, manajer perusahaan, dan manajer restoran. Barista yang bekerja di 'Kopi Sebagai' berjumlah 4 orang dengan 1
Kepala Barista, selain itu juga manager perusahaan berpengaruh dalam koordinasi mengenai ketersediaan bahan baku minuman kopi dan juga manager restoran yang menguhubungkan karyawan di 'Kopi Sebagai' dan restoran pada pihak perusahaan. Selain itu tedapat sumber daya fisik yang dimiliki oleh 'Kopi Sebagai' adalah mesin - mesin pembuat kopi yang tersedia di bar 'Kopi Sebagai'.

7) Key Activities

Aktifitas yang dilakukan 'Kopi Sebagai' untuk mengembangkan bisnya dengan promosi di media sosial dan juga mengadakan event - event dengan pihak komunitas Sepeda Brompton. Kegiatan lain yang harus dilakukan oleh barista di 'Kopi Sebagai' yaitu melakukan pengecekan bahan baku untuk memastikan segala kebutuhan yang diperlukan untuk memproduksi minuman kopi.

\section{8) Key Partnerships}

'Kopi Sebagai' memiliki hubungan dengan PT. Agro Investama yang memberikan dananya untuk perkembangan bisnis minuman olahan kopi. Kebun di Pangalengan juga menjadi pemasok utama biji kopi Arabika yang digunakan oleh 'Kopi Sebagai' dengan jenis bibit Sigagar Utang. Minuman kopi yang dihasilkan berasal dari biji kopi yang 
sudah di roasting, 'Kopi Sebagai' melakukan kerjasama dengan pihak kopi lain seperti Kopi Armor untuk melakukan roasting biji kopi. Hal ini dilakukan karena proses roasting sangat memengaruhi cita rasa kopi, maka lebih baik dilakukan oleh pihak berpengalaman, sedangkan di 'Kopi Sebagai' belum ada pihak yang sudah biasa melakukan kegiatan roasting, selain itu juga 'Kopi Sebagai' belum memiliki alat khusus pribadi untuk melakukan kegiatan tersebut. Kopi Armor juga beberapa kali melakukan pembelian biji kopi pada pihak perusahaan, sehingga terjadi hubungan baik antara pihak perusahaan dengan 'Kopi Sebagai'.

Komunitas Sepeda Brompton adalah salah satu mitra yang terhubung dengan 'Kopi Sebagai'. 'Kopi Sebagai' memiliki hubungan yang kuat dengan komunitas sepeda brompron karena pihak perusahaan juga adalah bagian dari komunitas sepeda brompton dan menjadikan 'Kopi Sebagai' menjadi tempat berkumpul sebelum atau sesudah melakukan kegiatan bersepeda. Kegiatan bersepeda yang biasa dilakukan yaitu didalam Kota Bandung sehingga penyebaran informasi memgenai Kedai 'Kopi Sebagai' lebih cepat.

\section{9) Cost Structure}

Dana yang dikeluarkan untuk tetap mengembangkan 'Kopi Sebagai' adalah biaya pembelian stok bahan baku untuk kebutuhan pembuatan kopi, dan biaya yang cukup besar dikeluarkan untuk biaya gaji barista. Selain itu biaya yang dikeluarkan secara fisik adalah tempat duduk, fasikitas wc, mushola, jaringan internet, dan listrik yang dimaksimalkan untuk konsumen. dalam hal lain, promosi juga dilakukan untuk memperluas penyebaran informasi mengenai 'Kopi Sebagai' melalui media sosial seperti instagram. Secara keseluruhan, alur keuangan 'Kopi Sebagai' masih tergabung dalam alur keuangan restoran.

\section{Kanvas Model Bisnis 'Kopi Sebagai}

Hasil analisis 9 elemen Bisnis Model Kanvas pada 'Kopi Sebagai', menghasilkan kanvas model bisnis yang bertumpu pada elemen Value Proposition dan saling memengaruhi dengan elemen lainnya. Jika tidak ada proporsi nilai pelanggan, perusahaan tidak akan berjalan dengan baik di pasar (Jessica dan Indriyandi, 2017). Kenyamanan konsumen adalah faktor yang sangat diperhatikan oleh 'Kopi Sebagai, dengan hal ini berkaitan dengan Revenue Streams yang berasal dari konsumen dengan 
pembelian berkala yang dilakukan. Kualitas dari biji kopi yang digunakan oleh 'Kopi Sebagai' sangat diperhatikan karena berasal dari perkbenunan Pangalengan yang dikelola sendiri oleh perusahaan, 'Kopi Sebagai juga menyatakan konsep tersebut dengan from farm to table.

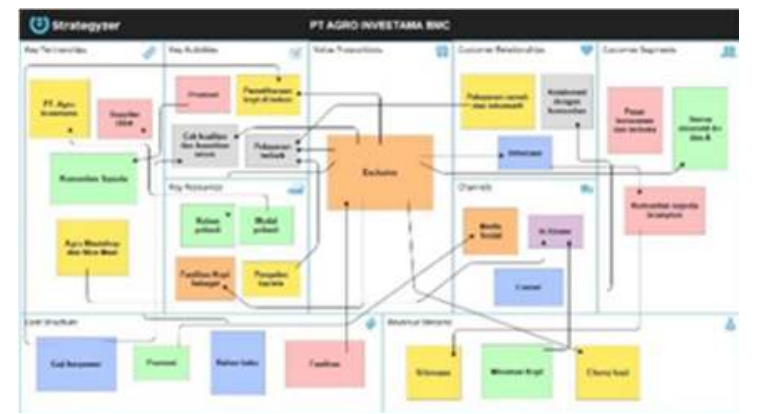

Gambar 1. Bisnis Model Kanvas 'Kopi Sebagai'

\section{KESIMPULAN DAN SARAN}

Berdasarkan hasil penelitian yang dilakukan mengenai kajian model inovasi agribisnis komoditas kopi menggunakan bisnis model kanvas, didapatkan kesimpulan sebagai berikut :

1. Bisnis Model Kanvas (BMC) yang diterapkan oleh PT. Agro Investama pada 'Kopi Sebagai' berjalan berdasarkan Value Proposition dari kualitas kopi jenis Arabika, fasilitas kedai kopi, dan komunitas sepeda Brompton. 'Kopi Sebagai' sangat memperkuat tingkat pembelian konsumen terhadap produk ataupun kenyaman yang diterimanya. 'Kopi
Sebagai' memiliki tujuan untuk memberikan nilai 'sempurna' bagi setiap konsumen yang datang dengan memberikan fasilitas lokasi dan kualitas kopi yang terbaik.

2. 'Kopi Sebagai' masih dalam proses pengembangan bisnis, baru berdiri selama hampir 1 tahun. Proses pengembangan 'Kopi Sebagai' masih berjalan dengan strategi promosi rutin membagikan gambar dan video mengenai aktivitas yang terjadi melalui media sosial Instagram. 'Kopi Sebagai' juga belum melakukan launch resmi, dalam 1 tahun ini perusahaan melihat minat dan kebutuhan konsumen terhadap coffeeshop tersebut upaya meningkatkan proporsi nilai bisnis.

3. 'Kopi Sebagai' menerapkan strategi inovasi penjualan From Farm to Table, yaitu setiap produk olahan kopi yang dijual adalah hasil dari perkebunan Pangalengan yang membudidayakan tanaman kopi Sigagar utang jenis Arabika. Hal ini adalah strategi dan sebuah ciri khas yang dilakukan perusahaan untuk menarik perhatian konsumen mengenai jenis kopi dan bagaimana proses yang dilakukan untuk membudidayakan kopi. 
4. Hal-hal yang dapat memperluas konsumen dan mengembangkan nama 'Kopi Sebagai' adalah cita rasa kopi yang khas dan kualitas yang baik berasal dari hasil penanaman sendiri, memberikan pelayanan dan fasilitas yang terbaik untuk kenyamanan konsumen, melakukan promosi melalui media sosial ataupun kegiatankegiatan yang bersangkutan dengan orang banyak atau komunitas, terutama komunitas sepeda Brompton.

Saran yang diberikan berdasarkan hasil analisis penelitian adalah sebagai berikut:

1. Perusahaan melakukan sertifikasi khusus kepada barista yang bekerja agar dapat memberikan ilmu yang lebih luas mengenai tanaman kopi dan juga memperdalam keahlian dalam mengolah minuman kopi.

2. Membuat web khusus mengenai 'Kopi Sebagai' untuk menyebarluaskan informasi mengenai Coffeeshop dan penjualan green beans sehingga lebih mudah di akses masyarakat luas.

3. Melakukan kerjasama yang lebih luas lagi untuk memperkuat aktivitas dan mengefektifkan pengembangan 'Kopi Sebagai'. Kerjasama dapat dilakukan ke beberapa komunitas sepeda
Brompton luar Kota Bandung, dan supplier kopi Arabika Kota Bandung.

4. Membuat tim khusus untuk melakukan roasting biji kopi sendiri dari pihak perusahaan untuk mengefesiensikan waktu dan biaya yang dikeluarkan.

\section{DAFTAR PUSTAKA}

Amit, R. Dan Zott, C., (2010). Business Model Innovation: Creating Value in Times of Change, Working Paper, IESE Business School, University of Navarra, Pamplona

Direktorat Jenderal Perkebunan. (2017). Statistik Perkebunan Indonesia 2015 -2017. Kementrian Pertanian. Retrieved 16 Juni 2019, from http://ditjenbun.pertanian.go.id

Hartini, S. (2012). Peran Inovasi: Pengembangan Kualitas Produk dan Kinerja Bisnis. Jurnal Manajemen Dan Kewirausahaan, 14(1), 82-88.

Internasional Coffee Organization. (2018). KATADATA. Retrieved 14 June 2019, from https://databoks.katadata.co.id

Kartono, D. T., \& Demartoto, A. (2015). SEBAGAI BUDAYA MASYARAKAT KONSUMSI: Studi Fenomenologi Pada Peminum Kopi Di Kedai Kopi Kota Semarang.

Kementerian Perekonomian. (2018). Independent Research and Advisory Indonesia, 2017. Roadmap Kopi Indonesia. Jakarta. Indonesia

Ostewalder, A \& Yves Pigneur, (2012), Business Model Generation. PT Elex Media Komputindo: Jakarta

Petersen, Soren. (2013). Culture as a Competitive Advantage. The Blog, HuffPost Business. April 2, 2014.

Prillyana, T. S. (2017). Perumusahn Strategi Untuk Meningkatkan 
Kinerja Coffee Shop XY. (227), 114.

Suradisastra, K., Edi Basuno dan Herlina Tarigan. (2014). "Status dan Arah Pengembangan Kelembagaan Petani”, dalam Prosiding Kinerja dan Prospek Pembangunan Pertanian Indonesia. Pusat Analisis Sosial Ekonomi dan Kebijakan Pertanian, Badan Penelitian dan Pengembangan Pertanian, Departemen Pertanian.
Jessica, N., Bisnis, P. M., Manajemen, P. S., Petra, U. K., \& Siwalankerto, J. (2017). Analisis Business Model Canvas Pada Tirotti Bakery. 5(3), 2-6. https://doi.org/10.1021/ja017692r. 